\title{
Zou Coronel nu tevreden zijn?
}

Citation for published version (APA):

Boorder, T. (1983). Zou Coronel nu tevreden zijn? Maastricht University. https://doi.org/10.26481/spe.19830325tb

Document status and date:

Published: 25/03/1983

DOI:

$10.26481 /$ spe.19830325tb

Document Version:

Publisher's PDF, also known as Version of record

\section{Please check the document version of this publication:}

- A submitted manuscript is the version of the article upon submission and before peer-review. There can be important differences between the submitted version and the official published version of record.

People interested in the research are advised to contact the author for the final version of the publication, or visit the DOI to the publisher's website.

- The final author version and the galley proof are versions of the publication after peer review.

- The final published version features the final layout of the paper including the volume, issue and page numbers.

Link to publication

\footnotetext{
General rights rights.

- You may freely distribute the URL identifying the publication in the public portal. please follow below link for the End User Agreement:

www.umlib.nl/taverne-license

Take down policy

If you believe that this document breaches copyright please contact us at:

repository@maastrichtuniversity.nl

providing details and we will investigate your claim.
}

Copyright and moral rights for the publications made accessible in the public portal are retained by the authors and/or other copyright owners and it is a condition of accessing publications that users recognise and abide by the legal requirements associated with these

- Users may download and print one copy of any publication from the public portal for the purpose of private study or research.

- You may not further distribute the material or use it for any profit-making activity or commercial gain

If the publication is distributed under the terms of Article $25 \mathrm{fa}$ of the Dutch Copyright Act, indicated by the "Taverne" license above, 
ZOU COMONEL NU TEWEDEN ZLJN?

Rede

Ujtgesproken bij de aronvaringe van het anbt wan gewoon hooglerat Jn de Arbeidseremestunde an do

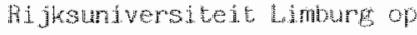
vri. juag 25 mart 1953 door

Dr. T.j. de Moorder 
a

druk: reprografie 
Zeer geachte tophoorders,

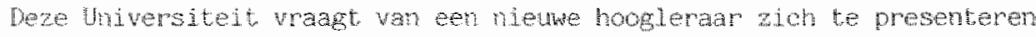
met en inangurele rede welke njet doorspekt mas zin met vaktechische termer, opdat room een breed gehoor duidelijk wordt wat het wakgebied

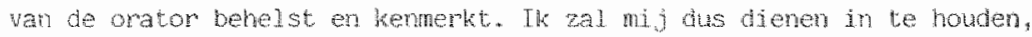
mar troost me met het pelt dat het unitersiteitsbestur cieze anwijzing woor oratoren geef met de velgende toelichting; "Aangezien aangenomen mare worden do de oraton de erkeming van zi jn vakgenoten rods heert werworven. "Het is duidelijk dat de vakgenoten onder het gehoor wandag dus geen grenswerlegsende visie op ons spejalisme mogen verwachter. Wietemin neem jk an dat deze omatie ook hen woldoende zal boejen.

Aan de Universiteit wath Amsterdam is verbonden het Coronel laboratoritum. Dit laborattoriun, onder de directie van Zielhuis, is genoend naar de medicus Samuel Semion Coronel, greboren inn 1827 te Amsterdam. Coroned studeerde in Amsterdam en in Leiden, waar hij in 1850 promoveende. Hij funktioneerde o.a. als stadsgenesheer in Zevenmuzen, later jn Middelbumg an Ansterdan. Deze geneesheer kwa - samen met een kleine kring college"s - tot de overtuiging, dat: het medicinal. therapeut soh handelen bij wele ziekch, met mane bij epidemieen van geringe betekenis was in verge lí.jking met wat

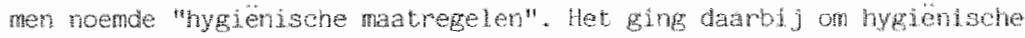
aspekten wh stedebow, husenbow, drinkwaryooryienting, woedine, Kleding, wulverwijgering en de arbejdshysjerne in bedrjuven. Te begimen in de periode dat Coronel in Middelburg werke, werd hi. dagelijks geconfronteen met ziekter die siechts door hygienische

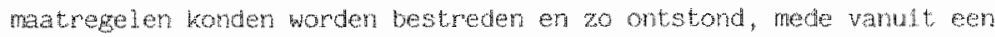

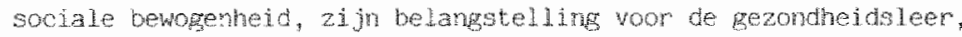
voral met betrekking tot de arbeidshygiene. 


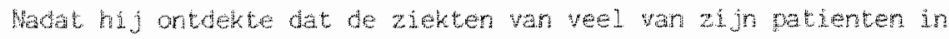
bethewh stonden met de onstandigheder waronder zij dr de fabrieken

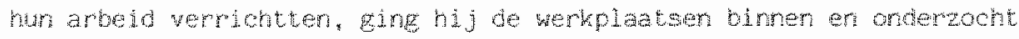

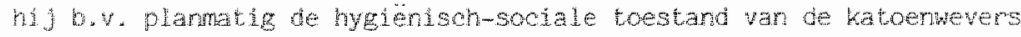

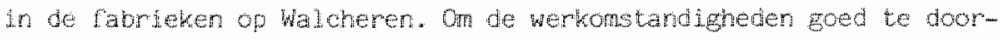
gronder, leerde hid zelf te weven an won men hem in latere jaren

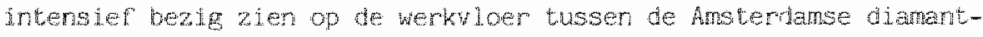
s) jpers an in de Hilwersurse texielfabrieken. In zijn boek "Gezoni

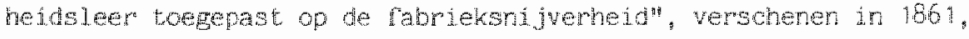
bijet hij op de scharelijke effecten voor gelwh en gezondheid var fabrieksarbeld en geert hij an hoe matregelen tot verbetering kunnen worder getrarfen. De mechanisatie in de industrie juichte Coronel toe, ondat dit zi jns inzims bijdroeg tow ex meer menswardigen bestaan var

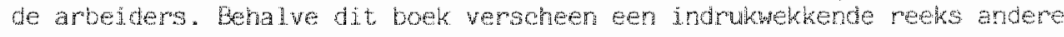
publicates var zijm hand ovem de arbeidshyjere. Hij wees op de slechte ver lichting bi het werk van de katomevers, over hun slechte houding bij het werk en his vond bij hen chromische andoenthgen var de luehtwegen door de vemontreiniging var de lucht met de vezels var het geren. Hij onderzocht de pap die gebukt werd bij het appreteren an wond daar-

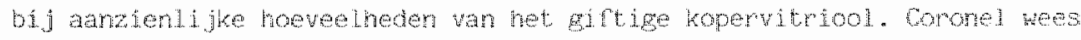
op de noodzakel ijkheid var beveiliging wan werktuigen, hefoonen, raderen, schreef dambj.j nawsluiterde kleding vor en wees op de gevaren van lawari. an hoge temperaturer.

Bij de dianantsijijpers in Amsterdam werd de diamant in lood gavat om hem te kunnen hanteren. Het lood ward hierbij gesmolten op en houtsm kolvumbje, en terslotte in het juste model gekneed met de vingers die hientoe met speeksel werden bewohtigd. Coronel tonde an dat bij deze gran wan zakn ontoelatbare concentraties koomonoxyde in che

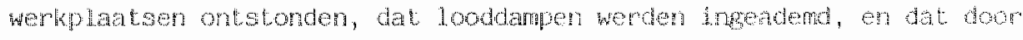

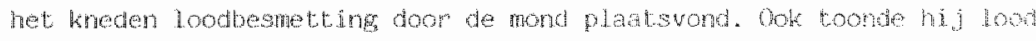

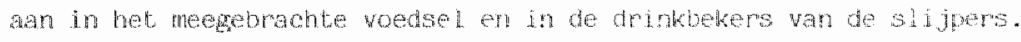

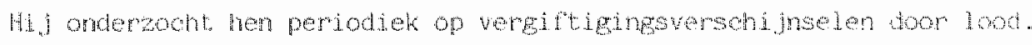

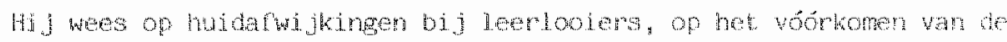

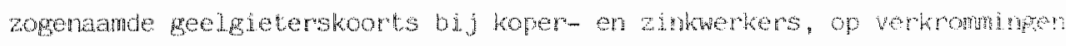
wan de werwelkolom bij stalwerkers, op anzienlijk le hoge ramentraties kooldioxyde in slecht geventileerde labreksminten. Hij ondersolide stor bestande wit ronde noleculan als in meelfabraken, or het scherpe 


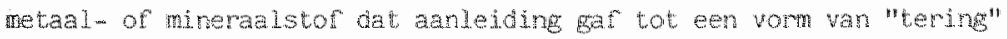

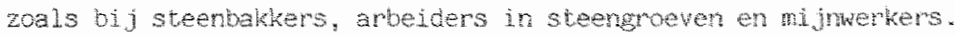

In 2 ing meestal gepronorcenge, mar altije goed onderboude adviezen richt coronel zich tot de werkgevers, spart ook de werkmemew zel niet en dringt aan bij de overheid, toen de ministen var binnerhandse zaken Thorbeke, op wettelijke matregelen. Deze vienhek: werkgevers, werknemern, ovemeid en deskumben womt ok nog heden ten dage het ramwerk warbinen de bedrijfsgezoncheidszong zich ontwikelt. If ben wat uitgebrad geweest in mijn beschmijuine wan do activiteiten van Coranel om een acount te gever aan het peburen dat aen cunatier werkend arts zion gat interesseren woor zuekrakende faktoren in de werkstutie. Met andere woorden: er wort een nelatte gelegr tussen ziekte en werk. De arts verlact zin sprekkmen en gat zion in de

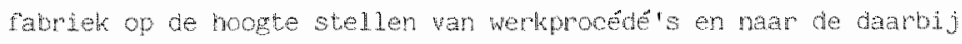
gebuikte stofier, eindprowkten, w de arbeidsonstandigheden welke welitaht de oomak zijn wan de ziekte bij zi jn patienten. Er is hen sprake van een doorbrak die wordt gevolgd coot en ontukkeling, die uteindelijk zal leiden nar het systentisch hestuderen wan de ralatie war werk en gezondheid.

De specifteke kennis vermeerdert zich dermate, dat het mogelijk wordt de belasting doo" de werksturite af te zetten tegen de belastbarheld van de werker, waarbij het problem wordt opgepakt deze grootheden zó

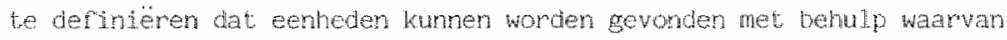
ze meetbaam worden gemakt. Als woobeeld kan hier menoend worden het

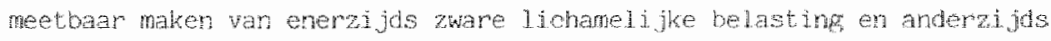
het vermogen van de mens om lohamel jhe inspaning te teverer. Hij het

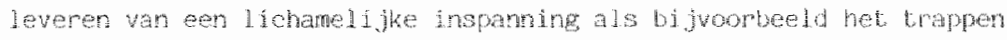
loper van een postbesteller met een tas me post, word in het lioham

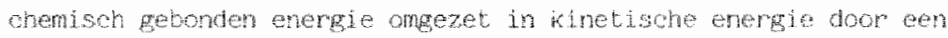
oryatieproces dat mogelt jk wordt door de opname van zutstof wit de

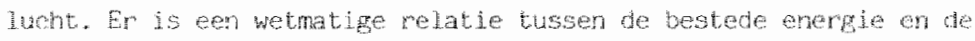
per minut ongenomen zumstof. Het zumstofebruik per minut is zo

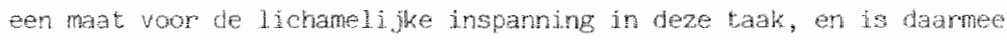

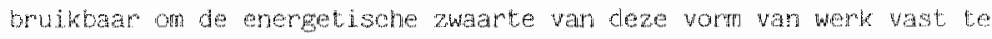
stellen. Uit onderzok is bekend hoe groot het wermogen wan de nens 


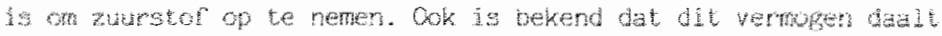

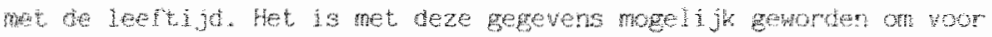

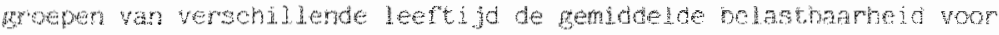

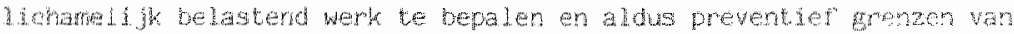

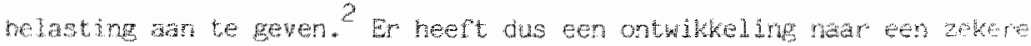

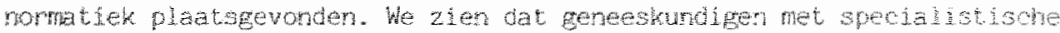

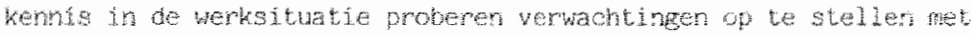

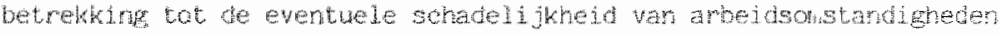

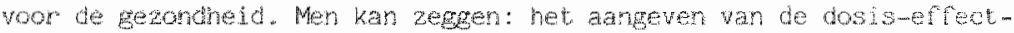
relathe. Deze geapcialiseerde geneskundgen worden genoend bedriffs-

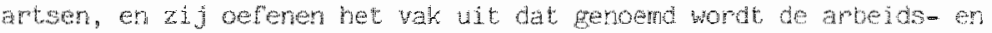

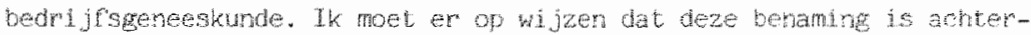

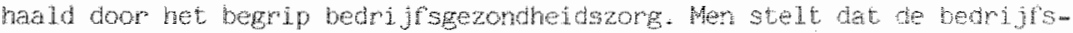
arte niet curater, met genezend optreedt, mar gezondhejozorg bedrift, met name dat deel van de gezondheidszorg dut zion bezig hout met de relatie var de mers an zijn ambeld, en dat een vorm van preventieve zorg is.

Aar deze briversitelt heert mer als erste in Nederland een dentete grote warde gebecht an dit deek van de gezonoheidszore dat mer bespter heet de leerstoel in te stellen die vandag formed wort andart met deze oratie. Th kan u verzekeren dat de college's in de bedrijfsgezondheidszorg jaren hebber witgezien mar het tot stam Women van dit ordinariaat, en grote wardering hebben wor deze beglissing, welle getugt vam het voomitstreverde beleld van de Gijksuniversiteit Limburg. Het is, gezlen deze voomitstrevendheid Jets vernasend dat her geozen is woor de eigenlijk verouderde naam arbeidsgereeskube, nar ik heb or wrede mee. Ik wind het elgentije wed een moot word. Het wijst meer op en relatie met arbeid dan met

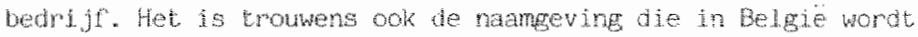

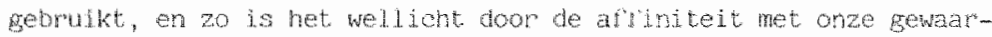
"Hesde buren dat her voor "anbeldsgeneskunde" is gekozen.

A.s we bedenken dat het meer dan eer eew geledem Is dat Coronel op te zo juist gesohetste wijze zjon weg vond nato de bedrijuen, dar kan de vraak gesteld worden of wij nu ved verder zijn, en of Coronel mu tevereden zou zing. 


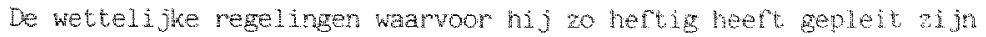
er gekomen. Een reeks van wetien en konnklijke besluiter geet op het agenblik min of meer strimgente beschermence vorschrinten voor

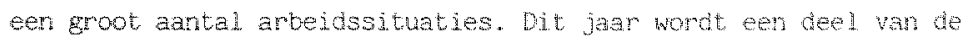
rieuthe hroeidsomstandighedentet var kracht. Zelfs in Europes verband zi jm regels opgesteld, zoas de Aarbeveling van de Commissie wan de EEO met betreking tot bedrifsgeneeskundige diensten in ondememinger bitgewardigh in 1962 .

Ook verschijren anbevelingen van de Internationale Arbeidsonganisatie (TLO).

Er zijn mu bijna 800 bedrijfsartsem in Neder-land wemzaan, on het aantal doo hem verzomgde werkemers is ruin 1,5 miljoen. 3 En zijn grote bedrijuen die eer relatief grote bedrijfsezondheidsdienst an zich hebben yembonden. Deze grote zogenande enkelvoudige

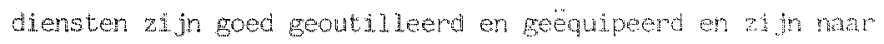
faciliteiten over het algemeen gericht op de specirieke problematiek varn het betrefence bednijh.

Haast de enkelvoudige diensten is er een vertigial gezamentike diensten, meestal in stimtingsom. zij behrotigen regional a bedrijfsgezondherciszorg yor te bedrijuer die zich bij de stichting

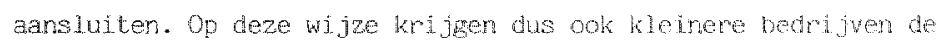
mogelijkhed adekwte bedrijrsgezondheidszorg nar we trekken. In de besturen van deze diensten zijn werkgevers en wembermere over het abemeer paritaje vertegenwoond get.

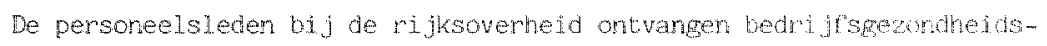
zorg door de Rjks Gemeeskuntige Dienst, voomzover er geen andere megeling is getroffen, zoals woor de rar, welk stateberijij eep eigen bedrijfsgezondheidgdienst berit.

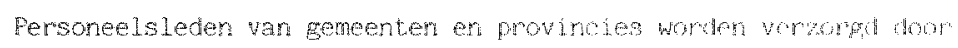

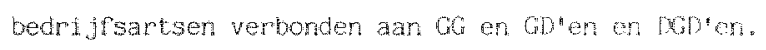

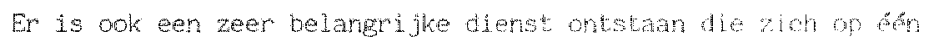

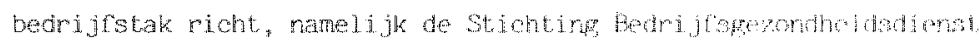
voor de Dowhni jventheid.

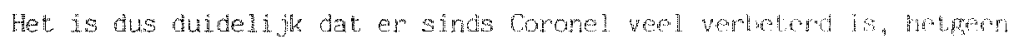
niet wegreent dat er nog wel enge opnerkingen to maker $z$ in hi de situatie wan varidade. 


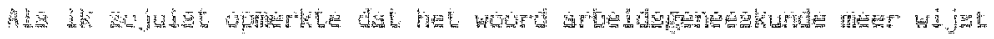

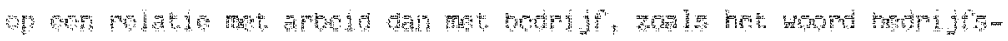

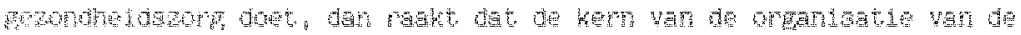

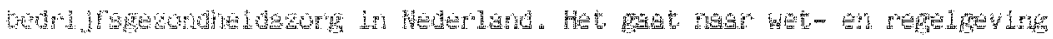

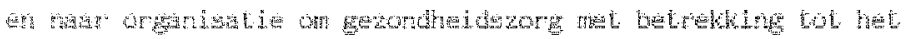

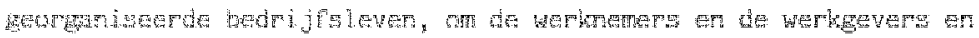

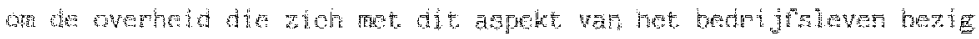

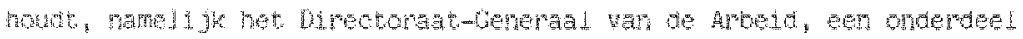

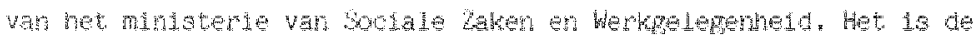

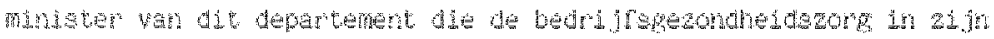

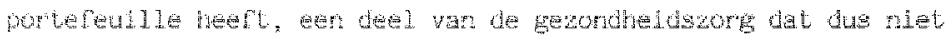

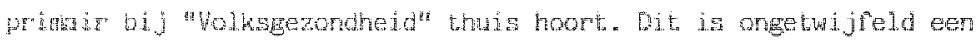

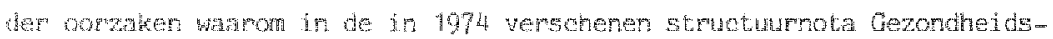

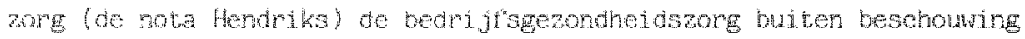

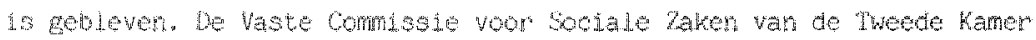

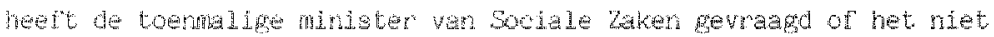

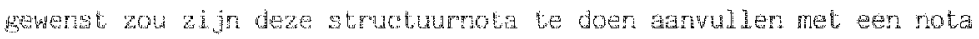
die de orgariatide van de preventieve gezondheidszorg in wemand met de arbeid meer in beald brengt. Deze aamullende mota, gerarand "de Lokomst wan de bedrijogerondheidszong", js ir 1979 werschenen en vormt de basis van het denken over bedmifiggezondheidszom mar inhou, personele invaling, organsatie, franciening, wetenschappelijk onderzok en onderwijs.

Voorzover hat de wettelijke regelingen met betmeking tot bedrijfsgezondheidszorg betrelt, richt de aandacht zich op het ogembik op de wet van 8 noveriter 1980, houdende bepalingen in het belarg van de veiligheid, de gezondheid en het welzijn in verbend met de arbeid, de zojuist genoende Arbeidsonstandighedenwet. Ook deze nieuke wet legt de varantwordelijkheld voor goede bedrijlsgezondheidszong ween bij de edrder genoende parti jern: werkgevers, werkmemers, overheid en deskundigen. De betrokkenheid wan deze wier partijen bij de bedrigesgezontheidsorg is wan invloed op de kwat teit daarvan.

De direote verantwoondeli jkheid woom het antrakken van bedrijusgezondheldszong heeft alt jd pmimein gelegen bij de werkgevers. Het is zeker zo dat vele van hen het belang vary deze zorg hebben onderkend en, okk als dat niet wettelijk verplicht was, een bedrijtsgezondheidsdienst hebben opgebowd of zich hebben angesloteri bij eer 
dergelijke gierst. Het mag genoend worder dat Philips in dit opatoht baanbrekend werk heeft vermicht met de opriching van een gezondheddsdienst onder leidimg wan Burger in 1928 .

Het is de ervamirg dat an werkgeverszjje nog al eens verwohtingen lever die gerioht zijr op een zeker rendenent, an dikw jis wat

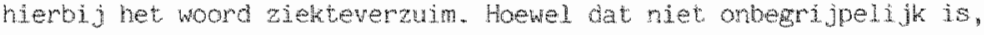
moet bedacht wonden dat verbetering van arbejometandigheden nut

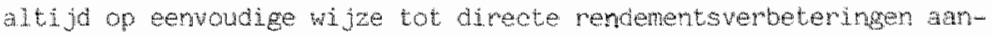
leiding geert. In Ge gewallen war dat wit zo blijkt te zijn, behoeft de berrijfsarts zich daarwoo zeker niet te generen, mar het gat prima ir om he beschemen var veilugheid, gezondheid en welzijn van de arbeidende populatie.

Meuw is in de Arbeidsomstandighedenwet dat de werknemens in grotere mate eer eigen werantwoordalijkheid met befrekring tot hum gezondheid en weiligheid bij fe arbeid word opgelegd. Th meten dat dit een zeer belanginhe zak is. Tijoens de arbeld is de aamdacht van wemkgver on werknemer witeraand zeem wericht op het arbeldsproces zelf, de technische an eonomische aspekten var de produltie. In de personele sfeer richt de belargsteling zich vooral op de prinaire arbeidswoorwarden zols salanis en primalre rechespostionele regelingen als vakantie, pensioenregelingen en dergelijke, of zelfs nog fundamenteler: werkgelegenteid. Hoewel dit zeer belangr jhe zaken zijn - er zeker op dit momert - meen ik dat van wenknemerszijde ten onmedwe een te geringe belangsteling heet bestan voor de arbejdsonstandigheden. Aan het eind wan de jarem zeventig ls daarin stulig verbetering gekonen, zoals 0.a. bleek uit de discussienota "Beter Wert" die in 1980 doog de wW is uitgebracht. 6 Deve belangsteling bijft echter nog te veel op het beleidsmiveau steken, en dalt onvoldoende af har de onderneminesraden en de werkwoer. Het val mite te omtkennen dat or hjerbij soms sprake is wan cen zeker watrouwen wen werknemersaijote, gevoed door het idee dat de kwall tel var de bedrijogezondheidszorg onwoldoende zou 21 jg en do onarhameli jkheid en cleshundigheld vam de bedrifsarto te geririg.

Het is wellicht hier de plats om lets dieper in te garn op envole aspekten van kwalleit in de bedrijfsgezondheidszong. Dit begrip moxt breed wonder opgevat; het gat om zaken als ongandsatief, financiering, outillage, pessonele bezetung van veelzijdige deskndigheid, weden- 


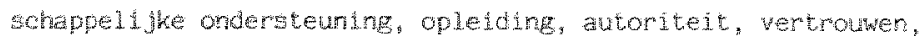
invioed op het bedri jobbeleid.

Een bedry jogezondheidadienst dient een ipfrastructur te bezthen Warbinmen deze aspester tot hur recht konen. Hen kar zegen dat deze infrastructur een zekre kritsche massa noet beztiten. Beneder deze kritische masa desintegreer de bedriffgezordheids-

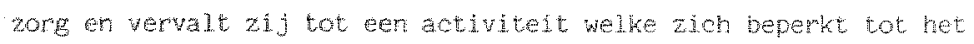

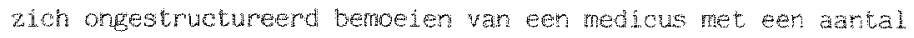
individuen in een tedrijf. Her is dujdelijk dat in deze infrastructur de rinanchering een belangrijke rol speet. In de eerder Senoende nota "De tokomst wat de hedrijrsezondhejdszorell wordt

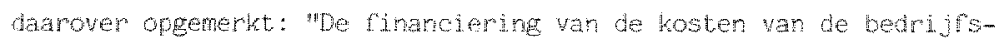
geneeshundige diengten heeft tot mu toe geen problerten gegeven ." De finanderine vindt bij en enkelwoudige dienst plats wh thet

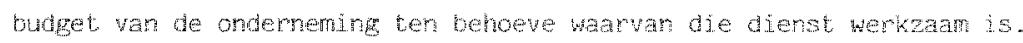

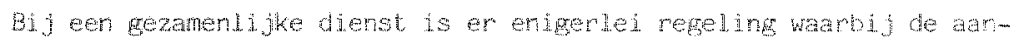
gesloten bermijuen de kosten betalen. Bi de overheldsdiensten homen de gelden in wezen uit de algemene middeler. De wijze war hraholerim

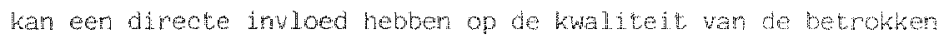

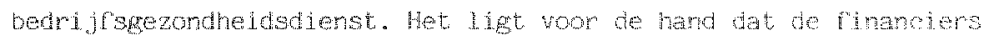
een belangrijhe insprat wensen bij de besteding van het budget. Het gevaar dat daamee en ongunstipe invloed op inhoue en omvang wan het takenpakket wan een bedrijfseroncheidsdienst word ultgeofend is allemingt derkbeddig. Onlangs wam fri.j het voonsel

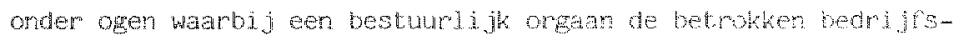

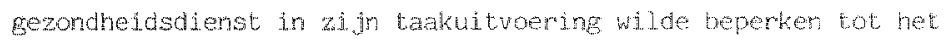
vermichten vam aanstelingskeuringer. zo jebs is ontoelagtbar. Er zou dan deen sprake meer zijn van bedri josgezondhe dszore.

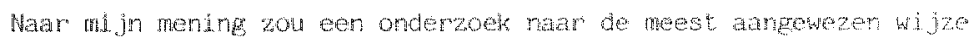

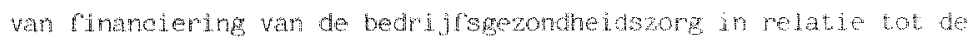

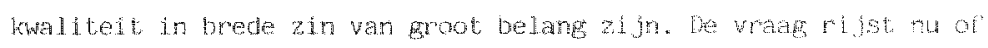

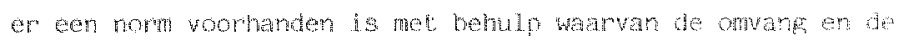

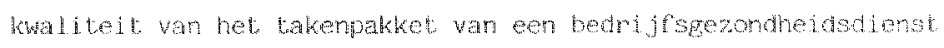

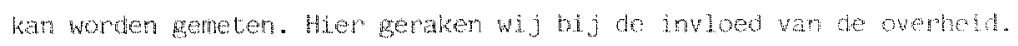

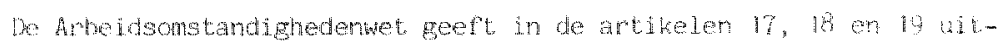

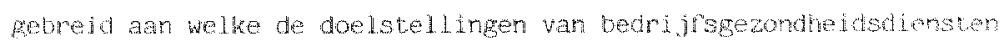
a in en welke takelementen noodzakel ijk zijn om dere doelstelitinger le bereiken. 
Dedri jwer wamin arbejd van industriele wari wordt vermich en die 500 of meer werkmens in dienst hebben, of beringen die specineke gezondheidsbeoneigende procéd s kenmen, zoals loodverwerking zijn bij de Verifgheidswet en straks bij de hrbeidsmotandighenwer ver-

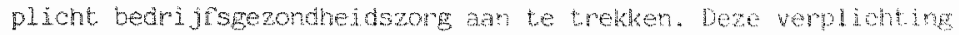

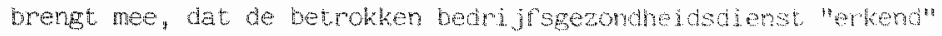
moet zijn. Dat wil zeggen dat de betrokken diengt mp kaliteit wortt getoetst doon de medsche diemst wan de Arbeidsinspede a

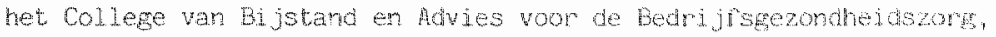
een college dat de Minister wan Sonalle Zaken en Wemelegeneh in deze aduseen. Fen bedrijfsgerondheidsuenst kn allem "enent zijm als er diensten wordra geleverd an een zogenam "verphom

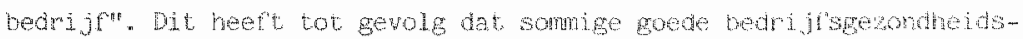

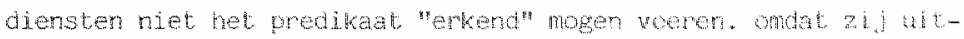
sluthend werer voor bedrijwen die de verplichting net is oppelegt.

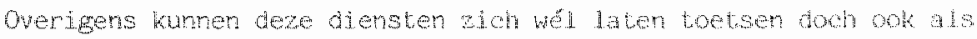
zij deze toetsing gord doonstakn, niet "enkend" worden.

We zien dis dat er wel degelijk een wettelijk onderboude nornt steling bestaat, welke enter de belangri jke bepenting heett slechts te gelder woor de diensten verleend an zogenamde verplichte bedriwer. wink stelt dat de hienbij goharteme minmumnormen vrij hoog gelegen zaijn, dow hij meent tevene dat er al wan een ammerke if fke overschrijding van deze nomem sprake is indien bijworbeeld op het gebiex van de anbeidshg lene deskundigen in een bedrijfsezondheidsdienst zijn opgemoner."

Ik kan het met Wrk eens zijn als hij er op wijst tat nog mar onkle bedrijfsgezondheidsdierster deze deskurdigen an zich hebber verbonden. Waar mijn mening zou echtem elke bedri josgezondheidsuienst moeter

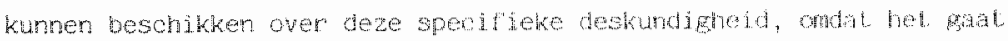

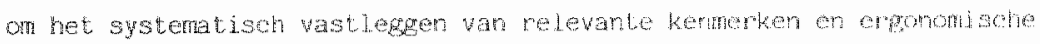
aspekten van de werkstuatie in ralatje net de rexondreidstoestana van de arbeidende vopulatie. zielhuts nomt aociale geneeskunde ean vom wan situatieve gerondhe idswom. Het bat in dit geval on de gezondheid en het melbevinden wan de mens in de stuatie ate wordt bepald door zijn arbeidsplex en doon 2 ijn arbeidsonstandighedon. De bedrifsarts hoort zon of die situatie te richten akt ap participerend, zods cononel op de werkylom, doch anders dar 


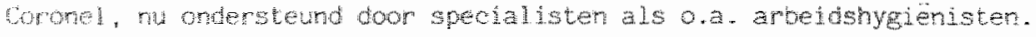
Terent hert he college van Bi jatand an Advies woor de Bedrijfspromble iazorg nast de determinaten me betrekine tot het kenmis-

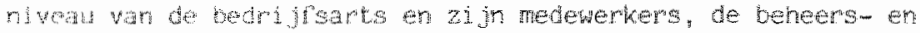

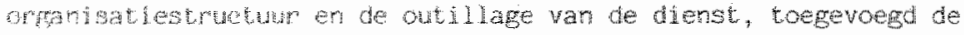

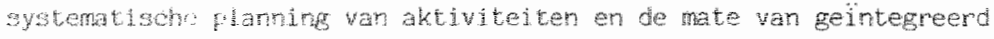

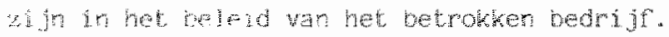

Mer" dar he for van de rond 750.000 wermentrs in het particuliere

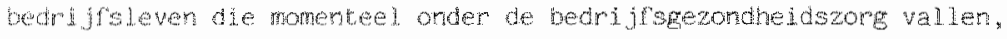
werkt echter miet in een zogendard "uerplicht bedpi jo".

Het is naturlijh werhetgend dat zo vele bedrijwen die riet werplichto

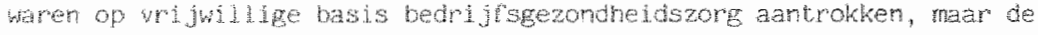
hwaliteit van de rong is dar dus niet wetwelith af te dwhgen.

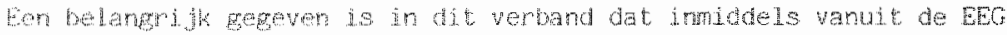

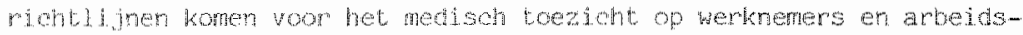

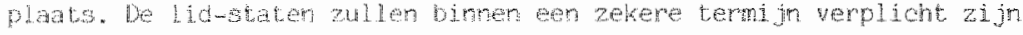

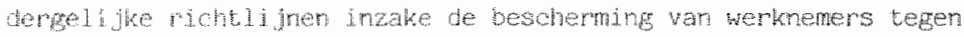
gevarlijke agentia, wals het monomene winyloblonde en het netallison lood, wit te voren.

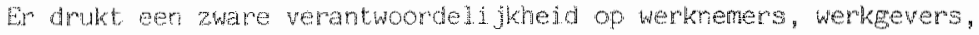

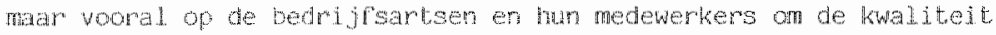
van de zorge te handhaven on op te weren en bij geringer wordende middelan de juiste prioriteiten te stellen en niek beneden de eerder genomde kritische masse te geraker.

Woon de personesisleden van de overheldsdienster $(+800.000)$ lijkt dit problem envoudiger. Volgens het Algeneen Rijksanbweraren Reglement heeft de ambtenar recht op bedrijfsgezondheidszong. In 1980 heeft de

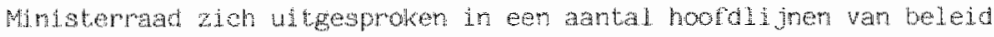
met betrekking tot de uitwoering van de Arbetdsontandighederwei voon het overheidspersoneel warin deze uitwoering voor het burgerlijk

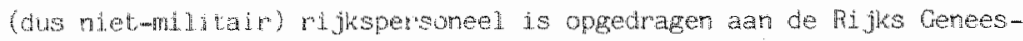

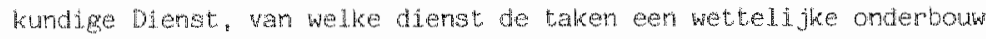
hebben. War wedri jf seeskundlge densten die voom het andere overheidspersoned werken zullen volgens deze hoofdijnen vam beleid de werkzamheden en voorschriften inhowdelijk in overeenstemmimg zijn met die van de Rijhs Geneeskndige DLenst. De praktijk leert ectuter dat bok woor de bedri jfsgezontheidszorg wor het overheidspersoneel kwalteitsbewaking dringend geboden is. 
Th benadruk dat de primaire zorg vor de inhoudelijke kaliteit

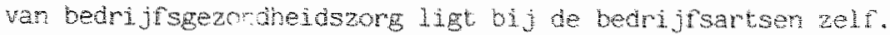
Het wetelijk afdwingen wan kwatited is dambij van seounda betekenis. Al in 1979 zegt Jongh: "de vraga lijkt mij wrgent wo men zonder stringente hepalingen van de overheid, dus op eiger intatatef de kwaliteit var de bedrijrsgeneeskumde zou kumem werbeteren. "Hj pleit voor een gezamenlik jo anpak whut de bedrithgezondheidsang zelr. De basis wan de hwalteit van de bedrijngezondheidszorg is de spectideke deskundigheid wan de bedrijfsarts. Zoals eerder onschmeven, heert zich ex proces voltrokken warbj jprake is var een wenplatsing van de velangetelling

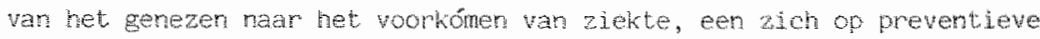
wijze michten ap gezondheidsaspekten van werk en werkonstandigheder. De bedri jesarts treft dar am belastingswomen van fysieke and (1.homelijke imspaming), van pereptief-mentale ard (b.v. het werker met beeldschermer), var psychosociale aard, fysische belastiresomen als geluid en straking en women wan chemisohe belasting. De geompliceendheid van deze wensohillence onderdeler ven zijn vak heeft tro to gelej dat de bedryfsarts vele andere deskumigen in zi jn werkgebied heept zien amriveren. Zo zijn te noemen de bedrijoverolegkundigen, arbeids-of bedrijhshygienisten (met al weer eigen specialister als acoustioi, chemoi, klmatdeskundigen), ermonomen, veiligheidskumdigen, gedrasswetensohappers als majschappelijk werkers, psychologen, sociologen, opleidens en vormers, organisatiedeskundigen, personeelsconsulenten en anderen. Het is woor de bedrijfsarts gen eenvoudige zaak oog te houden op de aktiviteiten wan al deze deskundigen en on samen te werken net al deze disciplines, warbj de specifieke beteknis war het arta-

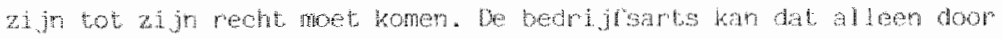
eem hoge mate vam spectieke deskundigheid te onthkelen; zonden

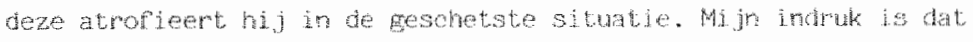
in wroegere Janen de wetenschappeli jke belangsteline wan de

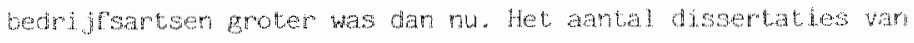

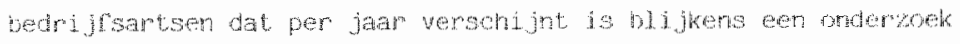

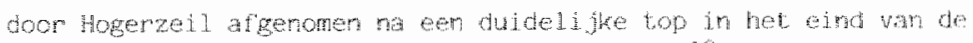
zestiger en het begin var de zeventiger jaren. 10 Mogelijh nert de

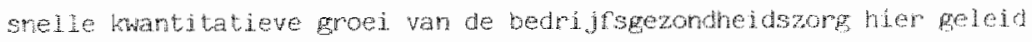
tot en zekere avitaminose. 
hopelith te nu de tijd gekomer dat ra deze exposieve groei eer

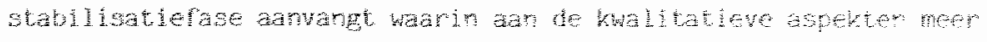

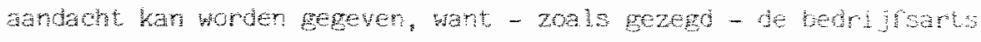

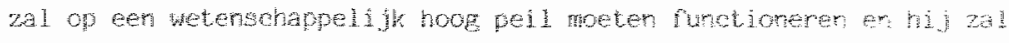

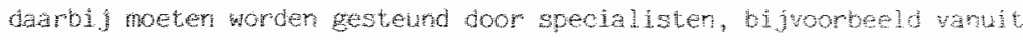
rwo-Ingtituten of universiteiten. Deze ondersteuning heept tot ru tos

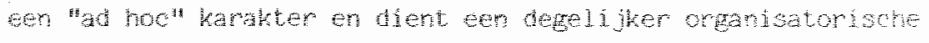

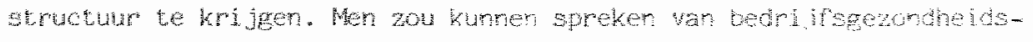

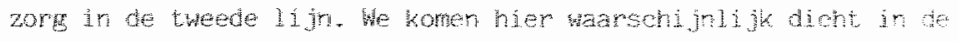

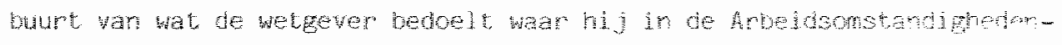

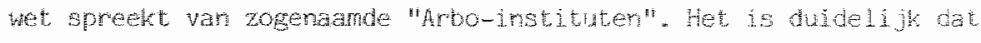
specialistische ondereteuning noodzakelijk is, mar ik wit met ken

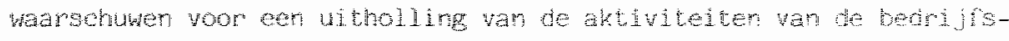

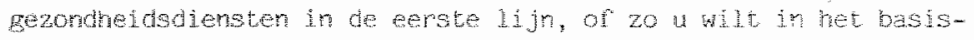
echelon. Mun ervaring met de wew mootste bedm jogerondheidsdensten

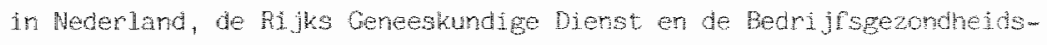
dienst war de pro welke djerster zalf btafafdelinger beziten die in belangrithe mate deze ondersteming vanut de tweede liju werponen,

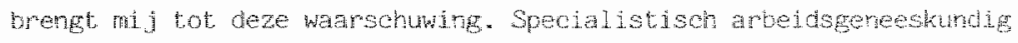
omderzoek in bedrifven mag suchts pladtsuirder met medewerking wan de betrokken bedrijfsartser. De positie van de bedrijparts in het bedrijf of de onderneming wordt ommoglijk indien hij door deskundigen vam buiten wordt geisoleerd. De bedrijfsants mag zich ook nief in die positie Jatem brengen door zonder voldoende ejgen onderzok en zonder het rormuleren van eer behoor ijke problemsteling hulp te vragen vam deze specialisten.

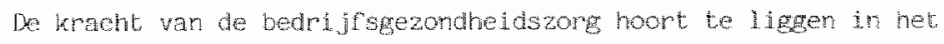
bedrif zelf. Th heb reeds eender betongd dat daarbij planmatig djert te worden gewerkt. Dat wil niet zegren dat er volgoms esm eviheidsprograma mot worder gehandeld. De verschillende arbeidswrmen an andasorganisaties vrager on een dambij passende bedrijfspezondheidszorg, mar de elementen wan dis zong moten op gestandaraseerde wijze wonder uitgevoerd. De betekenis van het handelan dient ook te worder geevaluetr. Mede ter ondersteuming van het beleid dienen daarom de bedrijfsgezondheidkundig relewant geachte kennerken van bedniji an werkplek in een gestandaandiseend informatiesystem gebracht te worden. 
Deze specinick arbeidsgebonden kermgegeven diener in relatie met persoonsgebonden gezondheishoundige gegeven met pideniologisone deskundigheid tot beleidswoorbeneing brikbar gentakt te worden. Aanzetten hiertoe zijn reeds gedam; ik wijs o.a. op publicaties van Heursing " Jemishens ${ }^{12}$ en stwmens $0 . s .13$. De beteknis van de epicmiologie voor becri jogemonoheidsong as

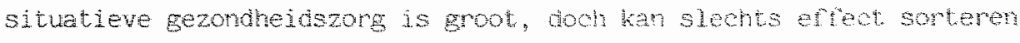

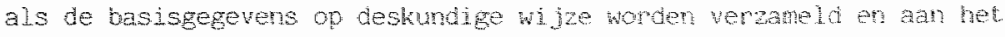
informatiesysteem worder toegevord. De keuze van de basiskerevens is zeer belangrijk, naar ook de wijze watrop ze wower gesignderd.

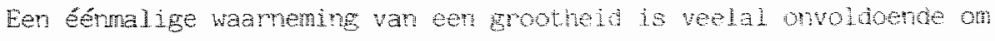
beleid op te bowwen. Hew ontwkeler wan een meetstrategie is dam noodzakelijk, hoewel dikwijh zeer gecompliceerd. Howel het begrip

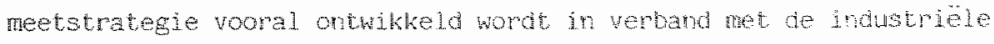
toxicologie is het achteriggende derkbeld ook vor andere werkileken gezondheidskundige gegevens, wellicht ook psychosodale, brukban. De gegevens die als resultat van epidemiologisch onderzok ter beschiking komen zullen op deskundige wi jze doo de bedringant moetery worden teruggebracht in de bedrijfssituatio un daa" geoperationaliseerd te worder bij de bescherming van gezoniheid, veiligheid en welzijn van de ambejdende mens.

De wrage dient zich owerigens ar, wat we precies bedor len met de arbeidende mens. Is dat de mens in het bedrijt, in de geopariseorte

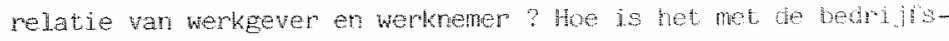
gezondhetiszorg voor de zelfstandige ambechtoman, de whiswenke", de hulisurouw ?

De aand van de arbeid en de onstardiphenen waroudel dis plasts

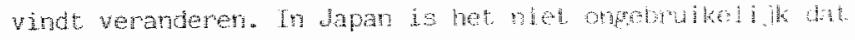

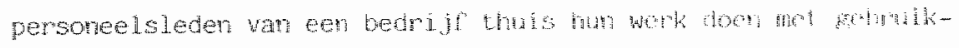

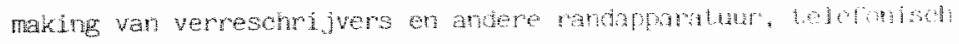

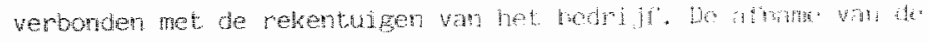

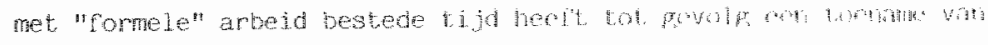

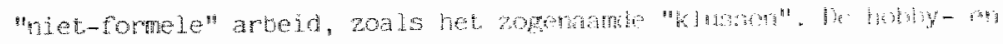

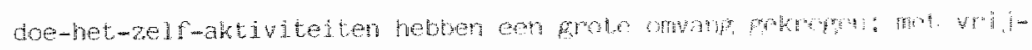

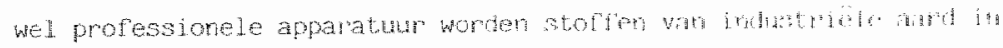

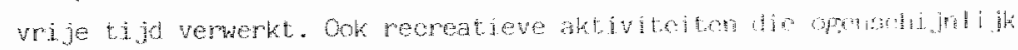




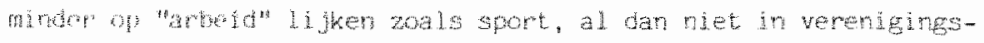

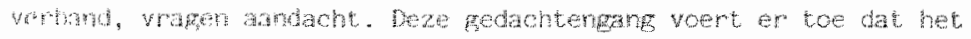

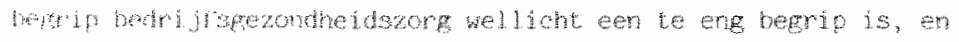

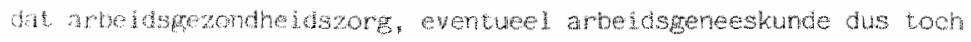

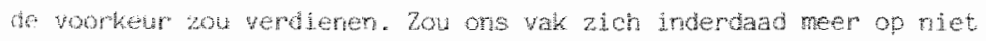

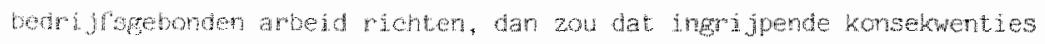

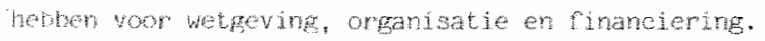

IJ min pletool wor een bedrifsarts op de werklek, als veen-

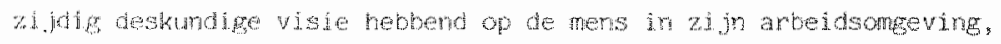
hen $1 \mathrm{k}$ er van alt tgegan dat on grootheden aan werkplek en mens

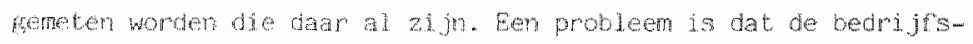

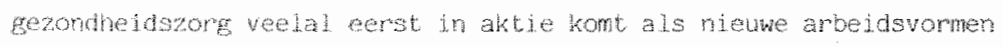

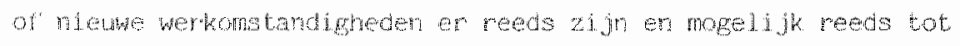

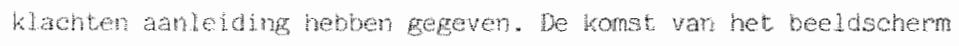
als algemen februth instrument heent ons ovemallen, op de

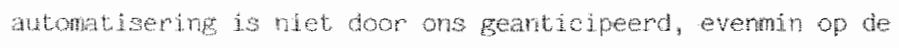
biolechiek. Jongh heent gepleit voom en studiesroep die en wisie ontwikelt op toekonghe arbeidssituaties en de invoed

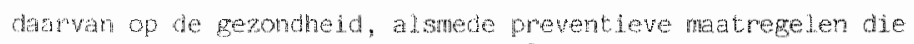

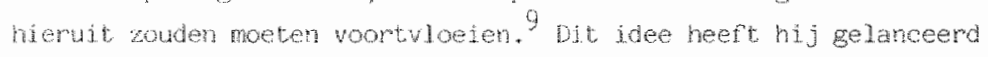

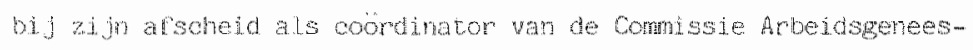
kundig Ondorzok van wh in 1979 en het is andsdien naet ulikgewerkt. Ik meen dat het van ferot welang is dit wel te doen. As basismateriad kan op dit monent dienem het rappot, kwatedt van de

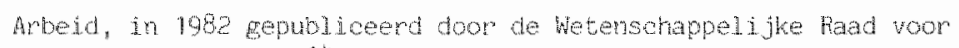
het Regeringsbelejd. ${ }^{14}$ op deze wiyze wordt de ontwikeling doorgetrokmen, the beginten met zen husarts die het idee heef dat de

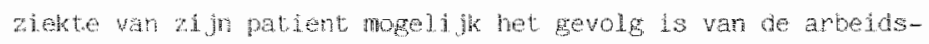
onstandigheder, dat eer bedrijharts die zich op gestruotureerde

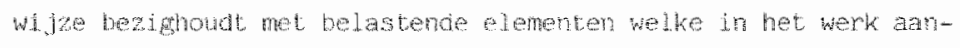

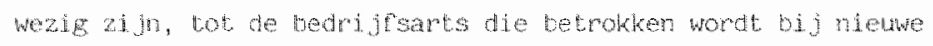
ontwhelinger in het ambeldsprowes, reeds voordat deze gerinplementeerd worden. 
Dames en Herer leden var het Universteitsbestum en van de

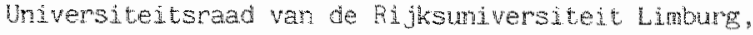

Ik dank yoor het wertrownen det U in mi hebt gesteld door mij woor te dragen vor he ordinariat dat ik neden fomed

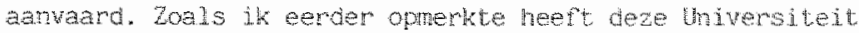
met het instellen van ean ieerstol frbeidsgeneesknde an blijk van gegever overtuigd te zijn var de betekenis wan de bedri jofsgezondheidszor

If zal mij volledig imzetren om deze opdracht nar beste humen wit te voenen, magn ik ben mij en wan bewust dat djt slechto iot het verwache resultat kam lejden met un sten en hup.

Dames en deren leden vam de faculteit der Gemeskunde en de Algenterie Racultejt,

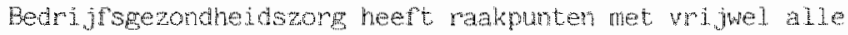
gebjeden van wetenschap welke $U$ tot de Uwe rekent. Wet velen van $U$ heb ik reeds gespreklen over samenwerking gevoerd. Gesprekken wejke hebben bijgedragen tot het stimulende gevol van vreugdevolle werwahting dat mis thang beheerst.

Lames en heren collegae bedrijfuntwen an andere werkens in de bedrijfisgezondheidszorg,

IK ben mij er war bewht dat U verwahtirgsvol gestend bent jegens de nieur beroende hooglemar in de Arbeidogeneskunde an deze Universiteit. Dat legt mij de zhane vephiching op mee te helpen on de kwaliteit var de bedrijegezondheidszorg

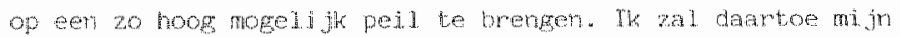
best coen, ragat we zul ler het samen moeten doen. Ik wrabe $u$ er an bij the dragen dat if ir dege funkte ntet geisoleord za raken wan "het veld", who op de wermioer dient ons wak gestalite to krigher.

Danes on heren studenten, Als 1 thet beshit mdemoeker te worden, treft $U$ an met einde var de we dia voont nam het antsdipjoma drie pootson zan. U zult motery beshissen door welke poort U Uw weg zult 


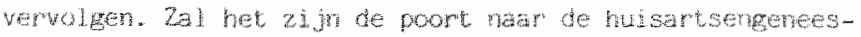

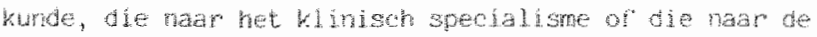
soclaje geneeshude ?

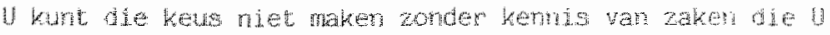
wor die tijd dant te hebhen verwomen.

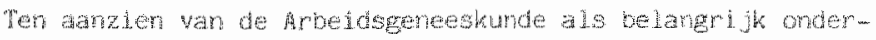

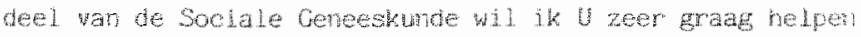
bj je werwerving wan deze kemis.

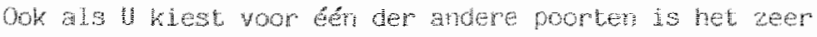

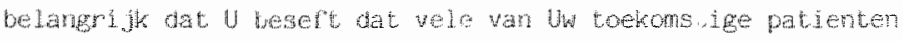

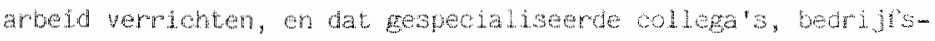
arbsen, whmen helper op het termejn wan de gezondhejdskundige arsekten darwan.

If dank it wow Uw aendacht. 
ITTERATUR

1. BemGMk, A.H. Semul Semor Comel, zijn betekenis wom de Sociale Cemeeskunte in Nederland. Assen, van Gomon, 1960.

2. Bothor, Tj.de. Enemgebesteding en lichemelijk prestatievermoger?

Scheveningen, Ekerbout, 1971.

3. Het bestand van en de vkatumes won antsen en verpleegkundigen bij bedrijfsgeneskmolige dienster op i-8-1982. Rapport Mederlands Institut voor preventieve Gezondineidszorg TNo. Eeiden, 1982 .

4. De toekomst wan de bedri jfsgezondheidszong. Uitgave Miristerie wan Sociale zakan an Werligelegenhejd, 1979.

5. vos, fi. Een bedri.jfsarts in het bedrif. Rapport ISM 82-SK-18.

Irstifuut voon Sociaal-Modische Wetenschap Ri jrsuriversiteit Gronkmen.

6. Beter Werk. Een MNY-discusstenota over de arbeidsonstandigheden en in het blizonder de gezordhela etr veiligheid in het werk.

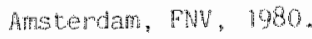

7. WIV A. Op weg natr de Arbodienst.

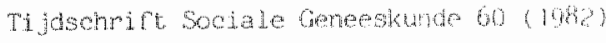
$206-213$.

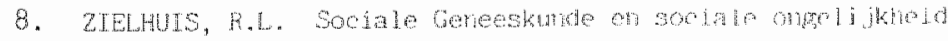
in gezoneshed.

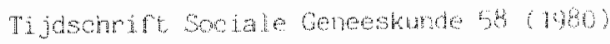
supplement par. $63-66$. 


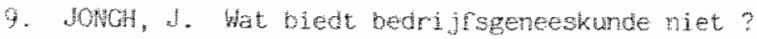
rijoschritt sociale Genestime 57 (1979) $296=300$.

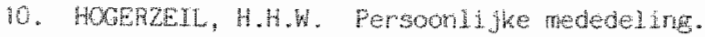

11. MEUnSMG, N.A. Problemen bij de registratie in de bedrt jogezondheidszong. Tijdsohrit Sodale Gereeskunde 5 ? (1979) $78-82$.

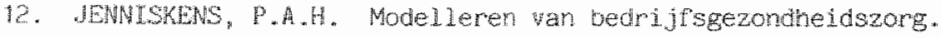
stichting bedrijfsgezondheidszorg West-Brabant 1982 .

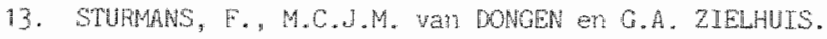
War een gezonde werkomgeving. Ni. jmegren, Dekker en van de Vegt, 198 .

14. Kwaliteit van de Hrbeid. Wehenschappelijke Rad voor het Regeringswieid. Rapport V $27-1982$. Staatsdrukkerij 1982 . 